\title{
The Effect of Promotion Integration Strategy on Sales Performance in the Context of Multiple Platforms: Considering the Moderating Effect of Platform's Market Demand
}

\author{
Jie Fang \\ School of Management, University of Science and \\ Technology of China \\ Jinzhai Road 96, Hefei, Anhui, China \\ fj2016@mail.ustc.edu.cn
}

\begin{abstract}
Price and promotion strategy have been widely discussed in multichannel retailing, but little study was focused on the promotion strategy in the context of multiple platforms. Through transaction data from a company's different platforms, our study investigated the impact of promotion integration strategy on company's overall sales performance on different platforms. Combined with platform's index data about product market demand, the moderating effect of platform's market demand was further evaluated. Using a fixed-effect model, our research found the positive effect of promotion timing integration and the negative effect of promotion depth integration on sales performance. We also found the moderating effect of platform's market demand. Thus, our study generates important theoretical and practical implications for managing promotion activity on multiple platforms.
\end{abstract}

\section{Introduction}

Nowadays, in order to get higher online market share, more and more companies sell products through more than one platform. On these multiple platforms, companies always do a lot of promotion activity by using the platform's various functions. Researchers suggested that there exists both synergy and cannibalization effect among multiple platforms $[8,11]$. Thus, it is crucial for companies to manage multiple platforms' promotion activity. Existing studies have discussed about the price and promotion strategy in multichannel retailing. Most of them suggested for the promotion integration strategy, which is defined as providing consistent price discount in the various channels simultaneously [16]. But some scholars have opposite opinion, such as [4] and [13]. That research has made contribution about promotion

\author{
Hefu Liu \\ School of Management, University of Science and \\ Technology of China \\ Jinzhai Road 96, Hefei, Anhui, China \\ liuhf@ustc.edu.cn
}

management in multichannel retailing. However, different channels have varied cost structural [23], which leads to the difference among each channel's promotion decision. But in the context of multiple platforms, such differentiation would be smaller. Moreover, customers can search and compare product and price information with lower costs in the context of multiple platforms than in multichannel retailing. Thus, due to the lower information asymmetry, the conclusion from multichannel retailing may not be suitable in the context of multiple platforms. Therefore, this study aims to investigate how to manage multiple platforms' promotion activity.

Marketing researchers revealed that promotion decision involves two aspects, which includes promotion depth and promotion frequency [9]. For retailers who enter multiple platforms, they must decide the extent of promotion depth integration and promotion timing integration. The former refers to the similarity of different platforms' discount rates for the same product, while the latter stands for whether retailers implement the promotion activity simultaneously in the different platforms. Hence, this study echoes the call of scholars [14] to investigate whether the promotion integration strategy (i.e., promotion depth integration and promotion timing integration) would influence company's overall sales performance on multiple platforms.

Moreover, existing literature suggested that the market environment would influence the effectiveness of company's business strategy [25]. Researchers have demonstrated that some contingency factors would moderate the effect of integration strategy, such as firm characteristic, consumer characteristic and product characteristic $[5,6,7,10,16]$. However, those studies ignored the platform's influence. Cross-side network effect have been emphasized on online platform, which refers to the effect that users on each side of the market benefit from the number of users on the other side and that demand is the driving force for user participation 
$[12,18]$. Hence, in the condition of high product market demand, there would exist more competing sellers on the platform, which further influence focal company's strategy effectiveness. However, there is limited study examining how platform's market demand influence the effectiveness of company's integration strategy [21]. Therefore, this study aims to bridge this gap by examining whether the platform's market demand relieve or magnify the impact of focal company's promotion integration strategy.

With the transaction data from a Chinese company who has stores on two online platforms, the current study investigated the impact of promotion depth integration and promotion timing integration on sales performance. Further, combined with the platform's product market demand index data, we evaluated how platform's market demand moderate the effect of promotion integration strategy. Our research employed a SKU (stock keeping unit) level fixed-effect model to generate several important findings. First, promotion timing integration can positively enhance sales performance. Second, promotion depth integration would negatively influence sales performance. Third, the enhancing effect of promotion timing integration on sales performance was weakened by higher platform's market demand.

Thus, this study contributes to the extant literature in the following ways. First, although the price and promotion strategy in multichannel retailing has been widely discussed, researchers did not focus on the context of multiple platforms. Second, we investigated the moderating role of platform's market demand on the influence of promotion integration strategy, which can contribute to our understanding of why the platform's market environment should be considered when making firm strategy. Finally, our study provides practitioners with valuable insights about how to manage the promotion activity on multiple platforms.

We first review the related literature and then present the hypotheses. Then based on our analysis and findings, we would explain the results and propose several future research directions.

\section{Literature review}

The price and promotion management in multichannel retailing has received much attention by scholars [14]. Most researchers support for the channel integration strategy $[2,15,19]$, which is defined as providing consistent information and integrated functions for customers in different channels [10]. For example, [15] demonstrated that providing consistent product and price information in varied channels can improve the information quality and customer's perceived value. Moreover, other scholars have diverse opinions about multichannel promotion management. For example, [23] suggested that it is possible for multichannel retailers to charge different price for customers in varied channels. Moreover, [4] pointed out that when the promotion is differed in terms of price discount and frequency, it would lead to the higher total sales. Nevertheless, [13] did not find significant effect of the consistent price on customer's channel choice.

That research has made contribution to the multichannel promotion management, but the focus is on the relationship of online, offline and other channels, such as catalog. Researchers suggested that different cost structural in varied channels would lead to the obvious differences among each channel's maximum promotion depth [23]. However, among multiple platforms, the difference about maximum promotion depth in varied platforms would be smaller. Moreover, in the context of multiple platforms, customers can easily get product information from various platforms. But such comparison and switching behavior incurs high cost in multichannel retailing. Hence, the information asymmetry is lower in the context of multiple platforms and the results of multichannel retailing may not be applicable.

In addition, firm's strategy may not always be effective in each situation [25]. Researchers also pinpointed out that it is important to investigate the contextual factors that influence the effectiveness of integration strategy [21]. Although some studies have found the effect of firm's characteristic, such as firm's experience in online and offline channels [5], human resource capability [16], consumer's characteristic, such as shopping experience [7, 10] and product type [6], little study has investigated the platform's influence. Existing researchers have revealed the cross-side network effect on platform [18], which reflects that users on one side would influence the growth of the other side [20]. Hence, customer's demand on the platform would drive more sellers to participate in the platform's competition [12], which may further influence focal company's strategy effectiveness. Although the effect of channel integration strategy has been demonstrated by a lot of scholars, it is still unclear about how it works in varied levels of platform's market demand. Therefore, this study tends to examine the moderating effect of platform's market demand on the relationship between promotion integration strategy and sales performance.

\section{Hypotheses}

\subsection{The relationship between promotion timing integration and sales performance}

Promotion timing integration refers to company's practice to implement promotion activity on varied platforms simultaneously. Existing studies suggested that integrated marketing communication can enhance 
customer's positive attitude toward the retailer [17]. In the context of online platform, company needs to implement a lot of promotion and advertising activity to attract customers and get higher Internet traffic. If company provides promotion activity in different platforms simultaneously, it would increase the company's exposure toward customers. Such repeated exposure can increase customer's awareness about the company and its offerings $[1,11]$, which can further increase customer's likelihood to purchase in the focal company. Therefore, we hypotheses that:

H1. Promotion timing integration is positively related with sales performance.

\subsection{The relationship between promotion depth integration and sales performance}

Promotion depth integration refers to company's practice to maintain consistent promotion depth on varied platforms. Although researchers suggested that inconsistent price information might increase customer's uncertainty and confusion toward the product and seller [15], in the context of multiple platforms, promotion depth integration might negatively relate with sales performance. Because different platforms have their unique characteristic, which is reflected by platform's operation style, consumers' preference and rivals' competitive strategy. Although price reduction is a useful way for company to attract customers and compete with rivals [22], if company remains consistent level of price reduction, it may limit the company's attractiveness and competitiveness on the multiple platforms [3]. Therefore, we hypotheses that:

H2. Promotion depth integration is negatively related with sales performance.

\subsection{The moderating effect of platform's market demand on promotion integration strategy and sales performance}

According to the cross-side network effect, the higher platform's market demand would drive more competitors to enter platform's competition [12], which can further increase product and service choices for customers. Although doing promotion activity simultaneously on varied platforms can increase customer's brand awareness, it may have limited effect on enhancing company's attractiveness to customers. In the condition of high platform market demand, the increased number of competitors and alternative offerings might decrease focal company's attractiveness, which thus lead to lower sales performance. Moreover, due to the limited competitiveness from company's promotion depth integration practice, in the condition of high market demand, alternatives' attractiveness would further magnify the negative effect of promotion depth integration. Hence, we suggest that:

H3a. Platform's market demand would negatively moderate the relationship between focal company's promotion timing integration and sales performance.

H3b. Platform's market demand would positively moderate the relationship between focal company's promotion depth integration and sales performance.

\section{Methods and results}

\subsection{Data description}

We have transaction data from a Chinese company during the period from January 2017 to December 2017. This company was founded in 2000 , who mainly sells the melon seeds through both online and offline channels. In the online channel, the company sells product mainly through two online platforms (TMALL.COM and JD.COM). These two platforms differ in terms of operation pattern, competition and consumer preference. TMALL.COM operates like "shopping mall", where exists large number of sellers who can individually manage their own stores and sell the products by using platform's function. While JD.COM combines the operation way of "supermarket" and "shopping mall". For the "supermarket" way, JD.COM purchases products firstly and then sells and deliveries products to consumers. On this platform, "supermarket" is the dominant way and the platform has multiple own warehouses in order to provide quick delivery services to customers. Hence, TMALL.COM exists more competitors and alternative products than JD.COM. Moreover, consumers always purchase for the low-price products in TMALL.COM, such as clothes, foods and cosmetics, but prefer to purchase for high-price products in JD.COM, such as electronic equipment and household appliance.

This company has their own stores in these two platforms and the sales from their own stores covers most of their entire online sales. In order to improve the sales performance, company always do a lot of promotion activities. For managing the promotion activity, marketing manager who takes charge of the one platform should plan the promotion activity in advance and get approval from the general manager. Their most common promotion way is price discount. By using platform's price discount function, the discounted products' website page would display the discount information. 
Table 1. Description statistics about business on two platforms

\begin{tabular}{ccc}
\hline Variable & TMALL.COM & JD.COM \\
\hline Total order number & 17336 & 19564 \\
Average order price & 23.21 & 30.85 \\
(s.e.: 11.28$)$ & (s.e.: 6.40$)$ \\
Average number of & 3.83 & 14.33 \\
$\begin{array}{c}\text { SKUs on promotion } \\
\text { per week }\end{array}$ & (s.e.: 3.15$)$ & (s.e.: 8.84$)$ \\
$\begin{array}{c}\text { Average percentage } \\
\text { of price discount per } \\
\text { week }\end{array}$ & $\begin{array}{c}17.04 \% \\
\text { (s.e.: } 0.1270)\end{array}$ & \begin{tabular}{c} 
(s.e.: 0.1089$)$ \\
\hline
\end{tabular} \\
\hline
\end{tabular}

The source data consist of 36900 records from two main platforms of the company. And Table 1 shows the basic information about company's business on these two platforms. Each record corresponds to one purchase order and fulfillment, which contains the transaction time, SKU name, the order volume of the SKU, the original price and transaction price for the SKU and other consumer demographic information. Given the diversity of its products, our analysis includes 10 SKUs which belongs to one product category (melon seeds) but with varied sizes and tastes. Because our data is based on transaction records, we aggregate the transactions at the SKU level in each week. Due to the existence of some time periods without any transactions on two platforms, the final aggregated data includes 301 observations. Moreover, for the variable of platform market demand, we have the platform's transaction quantity index about melon seeds in TMALL.COM. We also have the mainly 10 competitor's transaction volume data in each day in TMALL.COM and JD.COM, which are used as control variables in our study. The measurements of all the variables are listed in Table 2.

Table 2. Measurements of all variables

\begin{tabular}{|c|c|c|c|}
\hline Notation & Variable & Definition & Measurements \\
\hline Lnsales $_{m, t}$ & $\begin{array}{l}\text { Product sales } \\
\text { quantity }\end{array}$ & $\begin{array}{l}\text { Logarithm of SKU m's sales quantity } \\
\text { in two platforms in week } t\end{array}$ & $\begin{array}{l}\text { LN (sales quantity } y_{m, i, t} \\
\left.+ \text { sales quantity }_{m, j, t}\right)\end{array}$ \\
\hline prom_depth_integ $g_{m, t}$ & $\begin{array}{l}\text { Promotion } \\
\text { depth } \\
\text { integration }\end{array}$ & $\begin{array}{l}\text { The similarity of SKU's discount rate } \\
\text { in two platforms in week t, the dis- } \\
\text { count rate is calculated as the differ- } \\
\text { ence between original price of SKU } \\
\text { minus transaction price of SKU, di- } \\
\text { vided by the original price of SKU }\end{array}$ & $\mid$ dis_rate $_{m, i, t}-$ dis_rate $\left._{m, j, t}\right|^{*}(-1)$ \\
\hline prom_tim_integ $g_{m, t}$ & $\begin{array}{l}\text { Promotion } \\
\text { timing } \\
\text { integration }\end{array}$ & $\begin{array}{l}\text { The percentage of days that two plat- } \\
\text { forms have promotion simultaneously } \\
\text { in week } t \text {, divided by the total number } \\
\text { of promotion days in two platforms }\end{array}$ & \\
\hline compet_sales $_{i / j, t}$ & $\begin{array}{l}\text { Competitor's } \\
\text { sales quantity }\end{array}$ & $\begin{array}{l}\text { Competitor's sales quantity in platform } \\
\qquad i / j \text { in week } t\end{array}$ & $\sum_{n=1}^{n=10}$ competitor sales quantity $_{n, i, t}$ \\
\hline pre_sales $_{m}$ & $\begin{array}{l}\text { Previous } \\
\text { week' s sales } \\
\text { quantity }\end{array}$ & $\begin{array}{l}\text { SKU m's previous week' sales quan- } \\
\text { tity in two platforms }\end{array}$ & \\
\hline festival $_{t}$ & Festival & $\begin{array}{c}\text { Whether the week } t \text { has a traditional or } \\
\text { business festival day }\end{array}$ & $\begin{array}{l}\text { If week t has a traditional or business } \\
\text { festival day, } \text { festival }_{t}=1 \text {, else }=0\end{array}$ \\
\hline month_dumy $y_{t}$ & Month & $\begin{array}{c}\text { Each month is defined as the dummy } \\
\text { variable }\end{array}$ & 11 dummy variables for each month \\
\hline
\end{tabular}




\subsection{Model specification}

We developed a fixed-effect model at the SKU-week level to analyze the longitudinal dataset because the result of the Hausman test that we ran suggested that estimates of the fixed-effect model are consistent, while the estimates of random-effect model are not. Hence, we specified the following two fixed-effect models:

$$
\begin{aligned}
\text { Lnsales }_{m, t}= & \alpha_{m}+\beta_{1} \text { prom_depth_integ }_{m, t} \\
& +\beta_{2} \text { prom_tim_integ }_{m, t} \\
& +\beta_{3} \text { market_demand }_{t} \\
& +\beta_{4} \text { pre_sales }_{m} \\
& +\beta_{6} \text { compet_sales }_{i, t} \\
& +\beta_{7} \text { compet_sales }_{j, t} \\
& +\beta_{8} \text { festival }_{t} \\
& +\beta_{9} \text { month_dumy }_{t} \\
& +\varepsilon_{m, t}
\end{aligned}
$$

\subsection{Heteroscedasticity, serial correlation, multicollinearity}

To check for serial correlation, we used Wooldridge test to examine whether there is first order serial correlation. The results indicated the presence of first-order autocorrelation in our panel dataset $(\mathrm{F}(1,3)=66.473$, $\mathrm{p}$ $<0.000)$. To check for heteroscedasticity, we performed the Wald test to examine whether the errors are homoscedastic. The result indicates the presence of heteroscedasticity $\left(\left(\chi^{2}=242.88, \mathrm{p}<0.000\right)\right.$. These two issues

$$
\begin{aligned}
\text { Lnsales }_{m, t}= & \alpha_{m}+\beta_{1} \text { prom_depth_integ }_{m, t} \\
& +\beta_{2} \text { prom_tim_integ }_{m, t} \\
& +\beta_{3} \text { market_demand }_{t} \\
& +\beta_{4} \text { prom_depth_integ }_{m, t} \\
& \quad \times \text { market_demand }_{t} \\
& +\beta_{5} \text { prom_tim_integ }_{m, t} \\
& \quad \times \text { market_demand }_{t} \\
& +\beta_{6} \text { presales }_{m} \\
& +\beta_{7} \text { compet_sales }_{i, t} \\
& +\beta_{8} \text { compet_sales }_{j, t} \\
& +\beta_{9} \text { festival }_{t} \\
& +\beta_{10} \text { month_dumy }_{t} \\
& +\varepsilon_{m, t}
\end{aligned}
$$

\begin{tabular}{|c|c|c|c|c|c|c|c|c|c|c|}
\hline Variable & Mean & S. D & 1 & 2 & 3 & 4 & 5 & 6 & 7 & 8 \\
\hline Product sales quantity & 147.76 & 419.37 & 1 & & & & & & & \\
\hline $\begin{array}{l}\text { Promotion depth } \\
\text { integration }\end{array}$ & -0.16 & 0.15 & -0.48 & 1 & & & & & & \\
\hline $\begin{array}{l}\text { Promotion timing } \\
\text { integration }\end{array}$ & 0.14 & 0.27 & 0.51 & -0.11 & 1 & & & & & \\
\hline Platform's market demand & 49134.94 & 10834.47 & 0.16 & -0.22 & 0.09 & 1 & & & & \\
\hline Previous sales & 146.74 & 419.65 & 0.70 & -0.38 & 0.44 & 0.16 & 1 & & & \\
\hline $\begin{array}{c}\text { Competitor's sales quantity } \\
\text { in TMALL.COM }\end{array}$ & 103577.6 & 299286.5 & 0.16 & -0.12 & 0.13 & 0.07 & 0.21 & 1 & & \\
\hline $\begin{array}{c}\text { Competitor's sales quantity } \\
\text { in JD.COM }\end{array}$ & 25383.6 & 46564.99 & 0.00 & 0.03 & -0.02 & 0.07 & 0.02 & 0.13 & 1 & \\
\hline Festival & -- & -- & 0.05 & -0.04 & 0.02 & 0.04 & 0.04 & 0.13 & -0.25 & 1 \\
\hline
\end{tabular}

The only difference between the model 1 and model 2 is that model 2 adds an interaction term between two dimension of promotion integration strategy and platform's market demand, which tests the moderating effect proposed in our hypotheses.

suggest for using the fixed-effect model with robust standard errors [24]. We also checked for multicollinearity, the highest variance inflation factor is 3.25 , which is below the threshold of 10 . Moreover, the correlation analysis showed in Table 3 represents that the correlation between variables is satisfied. Hence, these results indicate that multicollinearity is not a major concern in our study.

Table 3 Correlation analysis 


\subsection{Results}

Table 4 presents the fixed-effect regression results for all variables with robust standard errors and the dependent variable is the SKU's sales quantity on two platforms. The results show that promotion timing integration is positively related with sales quantity on two platforms $(\beta=0.65, \mathrm{p}<0.000)$. Thus, H1 was supported. Promotion depth integration is negatively related with sales quantity on two platforms $(\beta=-0.72, p<0.000)$, which supports H2. Furthermore, the platform's market demand negatively moderates the relationship between promotion timing integration and SKU's sales quantity on two platforms $(\beta=-1.93, p<0.01)$, which support for $\mathrm{H} 3 \mathrm{a}$. But the moderating effect of platform's market demand does not significantly influence the relationship between promotion depth integration and SKU's sales quantity on two platforms $(\beta=0.28, p=0.36)$. Therefore, H3b was not supported.

\subsection{Robustness check}

In order to check the robustness of our estimation, several alternative measurements are compared. First, we use the sales amount as the alternative way to measure sales performance and obtained the same substantive findings. Second, we use the absolute price discounts to represent for promotion depth, which provide inferior results. Moreover, we aggregate the transaction data at each SKU's month level, which gives similar results.

\section{Table 4 Results of fixed-effect model with robust standard errors}

\begin{tabular}{|c|c|c|c|c|}
\hline $\begin{array}{l}\text { Dependent variable: } \\
\text { Product sales quantity }\end{array}$ & Model 1 & Model 2 & Model 3 & Model 4 \\
\hline $\begin{array}{l}\text { Promotion timing } \\
\text { integration }\end{array}$ & $0.65 * * *(6.46)$ & $0.65 * * *(6.50)$ & $21.20 * *(4.01)$ & $21.60 * *(4.16)$ \\
\hline $\begin{array}{l}\text { Promotion depth } \\
\text { integration }\end{array}$ & $-0.72 * * *(-8.95)$ & $-0.95(-0.24)$ & $-0.75 * * *(-10.64)$ & $-3.78(-1.22)$ \\
\hline Platform market demand & $0.83(1.07)$ & $0.84(1.27)$ & $0.40(0.52)$ & $0.53(0.82)$ \\
\hline $\begin{array}{l}\text { Promotion depth integration * } \\
\text { Platform market demand }\end{array}$ & & $0.02(0.06)$ & & $0.28(0.96)$ \\
\hline $\begin{array}{l}\text { Promotion timing integration } \\
* \text { Platform market demand }\end{array}$ & & & $-1.89 * *(-3.89)$ & $-1.93 * *(-4.04)$ \\
\hline $\begin{array}{c}\text { Previous week's sales } \\
\text { quantity }\end{array}$ & $0.20 * * *(5.93)$ & $0.20 * * *(6.55)$ & $0.17 * *(4.49)$ & $0.17 * * *(4.86)$ \\
\hline $\begin{array}{c}\text { Competitor's sales volume in } \\
\text { TAMLL.COM }\end{array}$ & $-0.05(-1.09)$ & $-0.05(-1.04)$ & $-0.06(-1.38)$ & $-0.06(-1.3)$ \\
\hline $\begin{array}{l}\text { Competitor's sales volume in } \\
\text { JD.COM }\end{array}$ & $0.28(1.44)$ & $0.28(1.45)$ & $0.31(1.71)$ & $0.31(1.71)$ \\
\hline Festival & $0.26(1.46)$ & $0.26(1.55)$ & $0.36(1.68)$ & $0.37(1.76)$ \\
\hline _cons & $-8.85(-0.94)$ & $-8.97(-1.11)$ & $-4.29(-0.47)$ & $-5.74(-0.72)$ \\
\hline SKU fixed effect & Yes & Yes & Yes & Yes \\
\hline Time fixed effect & Yes & Yes & Yes & Yes \\
\hline $\mathrm{R}$-square & $45.73 \%$ & $45.73 \%$ & $49.62 \%$ & $49.70 \%$ \\
\hline
\end{tabular}

Notes: $*$ sig at $0.05, * *$ sig at $0.01, * * *$ sig at 0.001 .

\section{Discussion}

The current research has studied the impact of promotion integration strategy on sales performance and considered the moderating effect of platform's market demand in the context of multiple platforms. The results show that promotion timing integration is positively related with sales performance, which is consistent with most studies' viewpoint that channel integration strategy can lead to positive firm level outcome $[5,16]$.
However, deviating from most studies in multichannel retailing, promotion depth integration is negatively related with sales performance, which indicates the negative side of integration strategy. The above findings complement the knowledge gap about the promotion strategy on multiple platforms [14].

Moreover, our study also uncovered the role of platform's market demand. We demonstrated that high platform's market demand would negatively influence the effect of promotion timing integration. This result supplements our understanding about platform's influence 
on the effectiveness of integration strategy [21]. But our study does not show the significant influence of platform's market demand on the effect of promotion depth integration. A possible explanation could be that when in the condition of high product demand, customers may engage in impulsive purchase and may not care about the nuanced differences in price and promotion in two platforms.

The findings of the current study also offer guidelines for managers to implement promotion activity on different platforms. Specifically, we suggest that providing promotion activity simultaneously on different platforms can lead to the synergy effect, which means that when company offers promotion simultaneously, the whole sales performance is greater than the simple sum of two platforms. But companies are supposed to decide the promotion depth according to consumer and platform's characteristics. Moreover, in the condition of high platform's market demand, the effect of promotion integration strategy is limited, thus companies should complement it with other marketing strategy.

We believe that our findings provide unique theoretical and practical insights about the effect of promotion integration strategy and platform's market demand. However, it still has some limitations that should be considered by future studies. First, the current study only provides the correlational results about the relationship between promotion integration strategy and sales performance. Future study can use field experiment to test for the causal effect of promotion integration strategy on sales. Second, due to the data limitation, we only focused on one company who sells nuts in China. Hence, the results of this study may not be appropriately generalized to other companies and industries. Future study can expand the sample size. Third, this study only considered the level of promotion depth and timing, future study can add in comparison of promotion type and company's deal support.

\section{Reference}

[1] J. Avery, T. J. Steenburgh, J. Deighton, and M. Caravella, "Adding bricks to clicks: Predicting the patterns of cross-channel elasticities over time," Journal of Marketing, vol.76, pp. 96-111, 2012.

[2] E. Bendoly, J. D. Blocher, K. M. Bretthauer, S. Krishnan, and M. A. Venkataramanan, "Online/In-Store Integration and Customer Retention," Journal of Service Research, vol.7, pp. 313-327, 2005.

[3] L. L. Berry, R. N. Bolton, C. H. Bridges, J. Meyer, A. Parasuraman, and K. Seiders, "Opportunities for Innovation in the Delivery of Interactive Retail Services," Journal of Interactive Marketing, vol.24, pp. 155-167, 2010.

[4] E. Breugelmans, and K. Campo, "Cross-Channel Effects of Price Promotions: An Empirical Analysis of the Multi-Channel Grocery Retail Sector," Journal of Retailing, vol.92, pp. 333-351, 2016.

[5] L. Cao, and L. Li, "The Impact of Cross-Channel Integration on Retailers' Sales Growth," Journal of Retailing, vol.91, pp. 198-216, 2015.

[6] O. Emrich, M. Paul, and T. Rudolph, "Shopping Benefits of Multichannel Assortment Integration and the Moderating Role of Retailer Type," Journal of Retailing, vol.91, pp. 326-342, 2015.

[7] D. Herhausen, J. Binder, M. Schoegel, and A. Herrmann, "Integrating Bricks with Clicks: Retailer-Level and Channel-Level Outcomes of Online-Offline Channel Integration," Journal of Retailing, vol.91, pp. 309-325, 2015.

[8] J. C. Kim, and S. H. Chun, "Cannibalization and competition effects on a manufacturer's retail channel strategies: Implications on an omni-channel business model," Decision Support Systems, vol.109, pp. 5-14, 2018.

[9] H. Kurata, and J. J. Liu, "Optimal promotion planningdepth and frequency-for a two-stage supply chain under Markov switching demand," European Journal of Operational Research, vol.177, pp. 1026-1043, 2007.

[10] Y. Li, H. Liu, E. T. K. Lim, J. M. Goh, F. Yang, and M. K. O. Lee, "Customer's reaction to cross-channel integration in omnichannel retailing: The mediating roles of retailer uncertainty, identity attractiveness, and switching costs," Decision Support Systems, vol.109, pp. 50-60, 2018.

[11] J. S. Lim, S. Y. Ri, B. D. Egan, and F. A. Biocca, "The cross-platform synergies of digital video advertising: Implications for cross-media campaigns in television, Internet and mobile TV," Computers in Human Behavior, vol.48, pp. 463-472, 2015.

[12] M. Lin, S. Li, and A. B. Whinston, "Innovation and price competition in a two-sided market," Journal of Management Information Systems, vol.28, pp. 171-202, 2011.

[13] K. Melis, K. Campo, E. Breugelmans, and L. Lamey, "The Impact of the Multi-channel Retail Mix on Online Store Choice: Does Online Experience Matter?," Journal of Retailing, vol.91, pp. 272-288, 2015.

[14] S. A. Neslin, and V. Shankar, "Key Issues in Multichannel Customer Management: Current Knowledge and Future Directions," Journal of Interactive Marketing, vol.23, pp. 70-81, 2009.

[15] L. B. Oh, and H. H. Teo, "Consumer Value Co-creation in a Hybrid Commerce Service-Delivery System," International Journal of Electronic Commerce, vol.14, pp. 35-62, 2014.

[16] L. B. Oh, H. H. Teo, and V. Sambamurthy, "The effects of retail channel integration through the use of information technologies on firm performance," Journal of Operations Management, vol.30, pp. 368-381, 2012.

[17] M. Reid, "Performance auditing of integrated marketing communication (IMC) actions and outcomes," Journal of Advertising, vol.34, pp. 41-54, 2005.

[18] M. Rysman, "The economics of two-sided markets," Journal of economic perspectives, vol.23, pp. 125-43, 2009. 
[19] H. Schramm-Klein, G. Wagner, S. Steinmann, and D. Morschett, "Cross-channel integration - is it valued by customers?," The International Review of Retail, Distribution and Consumer Research, vol.21, pp. 501511, 2011.

[20] P. Song, L. Xue, A. Rai, and C. Zhang, "The ecosystem of software platform: A study of asymmetric cross-side network effects and platform governance," MIS Quarterly, vol.42, pp. 121-142, 2018.

[21] P. C. Verhoef, P. K. Kannan, and J. J. Inman, "From Multi-Channel Retailing to Omni-Channel Retailing," Journal of Retailing, vol.91, pp. 174-181, 2015.

[22] P. Volle, "The short-term effect of store-level promotions on store choice, and the moderating role of individual variables," Journal of Business research, vol.53, pp. 63-
73, 2001.

[23] A. Wolk, and C. Ebling, "Multi-channel price differentiation: An empirical investigation of existence and causes," International Journal of Research in Marketing, vol.27, pp. 142-150, 2010.

[24] J. M. Wooldridge, "Fixed-effects and related estimators for correlated random-coefficient and treatment-effect panel data models," Review of Economics and Statistics, vol.87, pp. 385-390, 2005.

[25] V. A. Zeithaml, P. "Rajan" Varadarajan, and C. P. Zeithaml, "The contingency approach: its foundations and relevance to theory building and research in marketing," European Journal of Marketing, vol.22, pp. 37-64, 1988. 